\title{
Prediction of the Blast Furnace Process by a Mathematical Model
}

\author{
Xuegong $\mathrm{BI}$, Krister TORSSELL ${ }^{1)}$ and Olle WIJK ${ }^{2)}$
}

Formerly Department of Process Metallurgy, The Royal Institute of Technology. Now at Division of Ironmaking, Wuhan Iron and Steel University, 430081 Box 123, Wuhan, Hubei, People's Republic of China. 1) Formerly Department of Process Metallurgy, The Royal Institute of Technology. Now at ABB POWDERMET AB, S-735 00, Surahammar, Sweden. $\quad 2)$ Department of Process Metallurgy, The Royal Institute of Technology, S-100 44 Stockholm, Sweden.

(Received on September 9. 1991; accepted in final form on January 24, 1992)

\begin{abstract}
A prediction model has been developed based on the simulation model presented previously. These models are the two components of the KTH Blast Furnace Process Model. The concept of this prediction model is to use the same fundamental equations as in the simulation model and to use some output of a simulation of a blast furnace. Certain assumptions should be made for an individual change in operational conditions in order to build up the mass balance and heat balance submodels for the determination of the boundary conditions in a prediction. The ore to fuel ratio and the CO utilization are adjustable parameters in the model. The furnace internal state as well as furnace productivity and fuel consumption in the last iteration are considered to be the predicted results.

The prediction model has been designed for the following five cases: 1) increased blast temperature, 2) oxygen enrichment of the blast, 3) coal injection, 4) coal injection combined with oxygen enrichment and 5) changed coke quality. Moreover, this model can also be used for analysis of the thermal conditions in a blast furnace when an operational parameter, such as blast temperature, coke moisture and iron content in the ore, fluctuates.

The predicted operational indices were compared to the ones from industrial tests. The validity of the $\mathrm{KTH}$ model is indicated by this comparison.
\end{abstract}

KEY WORDS: ironmaking; blast furnace process; prediction; mathematical model; operational indices; thermal conditions.

\section{Introduction}

A previous article by the authors ${ }^{13}$ presents a simulation model of the blast furnace process. Based on this simulation model a prediction model has been developed in order to predict the internal state of the furnace as well as fuel consumption and furnace productivity when an operational action is taken (a case). This model can be used to analyse the thermal conditions in the blast furnace when some operational parameters fluctuate and to predict the thermal conditions as well operational indices for some selected cases.

The prediction model has been programmed in ANSI FORTRAN 77 and inplemented in Nord-500 and Vax minicomputers. By using the simulation results for a Nordic blast furnace, prediction tests have been carried out to make analysis of the thermal conditions in the furnace for three simple cases and to make prediction of operational indices for five cases. This paper presents the development of the prediction model and the prediction results by the model.

\section{Outline of the Prediction Model}

In order to predict the internal state of the furnace as well as fuel consumption and furnace productivity when an operating action is taken, a prediction model has been developed based on the simulation model. The basic concept of the prediction model is to utilize the same fundamental equations as in the simulation model and some output from a simulation of a furnace. The output include: 1) the correction factor for the rate of the gaseous reduction of iron oxides, 2) the correction factor for convective heat transfer between the gas and condensed phases in the dropping zone, 3) the ratio between the temperature of the condensed phases at the tuyere level and the flame temperature, and 4 ) heat losses through the furnace wall per tonne of hot metal.

\subsection{Division of the Furnace into Zones and Reactions}

The division of the furnace into zones in the prediction model is the same as in the simulation model, i.e. the lumpy zone, the softening zone, the melting zone and the dropping zone. The considered reactions are also the same, i.e. reduction of iron ore by $\mathrm{CO}$ and $\mathrm{H}_{2}$ gases, solution loss reaction of coke, gasification of coke by $\mathrm{H}_{2} \mathrm{O}$, decomposition of limestone, reaction between $\mathrm{CO}$ and steam, water evaporation, melting of reduced iron and slag formation. The correction factor $\psi_{22}$ for indirect reduction rate of iron ore in the softening and melting zones is maintained constant. Heat transfer 
phenomena in the furnace are assumed unchanged.

\subsection{Fundamental Equations}

The fundamental equations are also the same as in the simulation model except for the correction factor $\psi_{1 i}$ for the heat losses in the differential equation for gas temperature.

\section{Determination of Boundary Conditions}

\subsection{Upper Boundary Conditions}

The nonlinear equation system is the same as in the simulation model. However, two important parameters in the system, i.e. ore/fuel ratio and $\eta_{\mathrm{co}}$ are calculated from the operating data in the simulation model, while they are adjustable parameters in the prediction model in order to satisfy the lower boundary conditions of the Ordinary Differential Equation (ODE) system.

- composition of raw materials and products are kept constant,

- the slag/hot metal ratio is constant,

- the limestone/hot metal ratio is maintained constant,

- the dust/hot metal ratio is constant, and

$-\eta_{\mathrm{H}_{2}}$ is kept constant.

As for the blast, its volume is assumed to decrease to such an extent that the raceway gas volume is maintained constant in the case of oxygen enrichment, and its oxygen content must be increased in order to keep a constant flame temperature in the combined case of coal powder injection and oxygen enrichment.

Mass flowrate of the hot metal, iron ore and coke together with volumetric flowrate and $\mathrm{CO}$ content in the top gas are output of the mass balance submodel for a set of ore/fuel ratio and $\eta_{\text {co }}$ values. Accordingly, mass flowrate of the slag, dust and limestone, $\mathrm{CO}_{2}$ and $\mathrm{H}_{2} \mathrm{O}$ contents in the top gas, degree of direct reduction and indirect reduction of $\mathrm{FeO}$ are also calculated.

\subsection{Lower Boundary Conditions}

The following assumptions are made to establish the heat balance submodel in the prediction model:

- temperature of the hot metal and slag is kept constant,

- heat losses are kept constant, and

- the ratio between the flame temperature and the condensed phase temperature at the tuyere level is kept constant.

The upper boundary condition of gas temperature is an output of the heat balance, and the temperature of the gas and condensed phases at the tuyere level are estimated iteratively by a half-way method according to Pehlke. ${ }^{2)}$

\section{The Order of Calculation in the Prediction Model}

The order of calculation is summarized in Fig. 1. First, initial value of ore/fuel ratio and $\eta_{c_{0}}$ is preset and data are read from the data base created in a simulation. Mass balance and heat balance are made to determine the boundary conditions. The solution of the ODE system in the lumpy, softening and melting zones are the same as in the simulation. The iterative process in simulation for searching the upper boundary condition

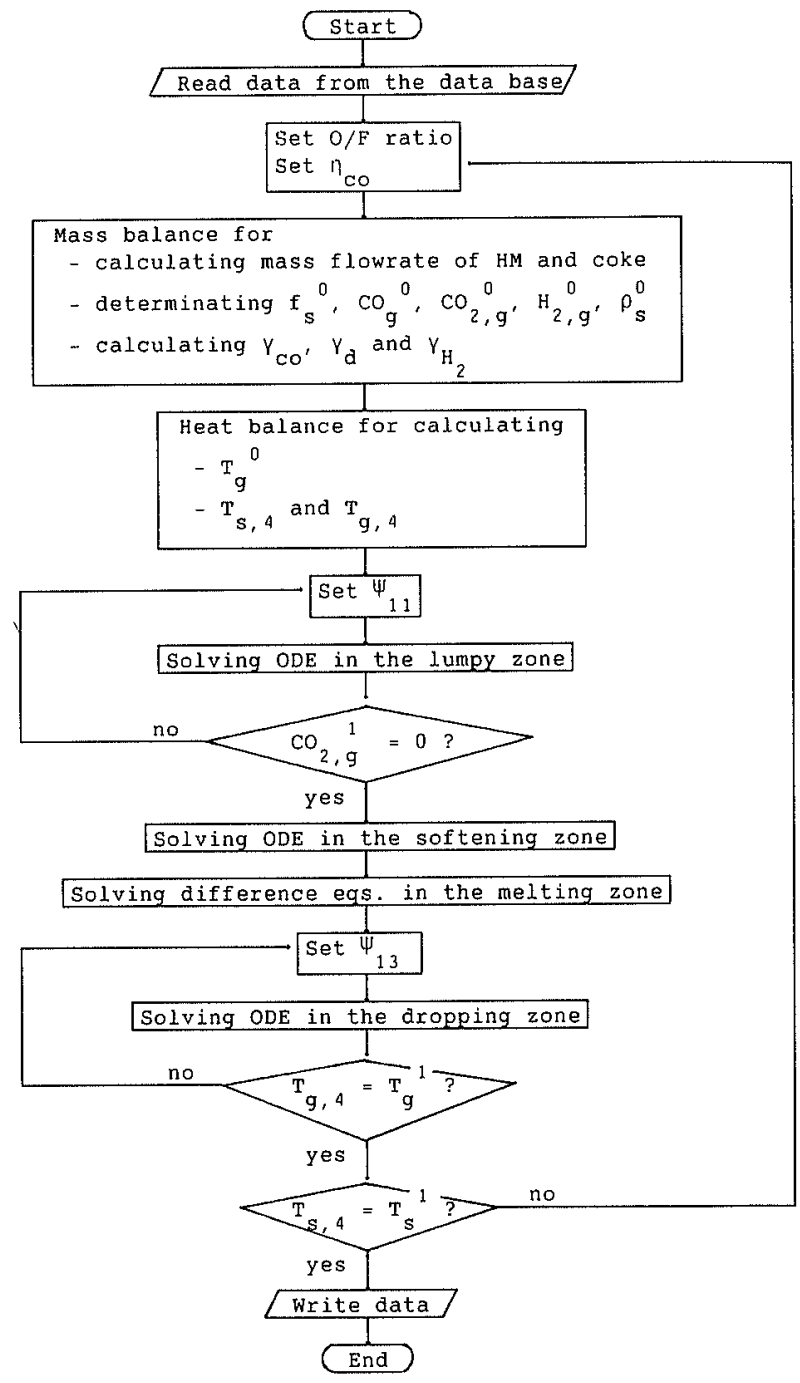

Fig. 1. Flow chart of calculation in the prediction model.

of gas temperature and for searching correction factor $\psi_{22}$ for the indirect reduction rate are no longer necessary in the prediction.

There is only one parameter $\psi_{13}$ for $h_{w}$ that should be searched in order to satisfy the lower boundary condition of gas temperature when the ODE system is solved in the dropping zone.

The determined temperature of the condensed phases at the tuyere level is supposed to be equal to its lower boundary condition. If not, a new set of ore/fuel ratio and $\eta_{\text {co }}$ must be presented and the calculation repeated.

When thermal condition in the furnace is to be analysed, which might be termed as a simple prediction, the ore/fuel ratio and $\mathrm{CO}$ utilization in a simulation test are used for determining the upper boundary conditions and the iterative procedure to search for the appropriate ore/fuel ratio is no more necessary. The calculated temperature of the condensed phases at the tuyere level does not satisfy its lower boundary condition because it is determined by the assumption that hot metal and slag temperatures do not change. The hot metal and slag temperatures could be estimated by an iterative procedure until the calculated temperature of the condensed phases at the tuyere level is equal to its lower boundary condition with the ore/fuel ratio and $\mathrm{CO}$ 
utilization being maintained constant. However, it is not necessary to do so for the purpose of analysing the thermal condition when an operating parameter fluctuates

\section{Analysis of Thermal Conditions in the Furnace}

In practical operation some parameters such as blast temperature, iron content in the ore and coke moisture fluctuate to some extent. It is interesting to analyze the thermal condition in the furnace when an operating parameter fluctuates and no counteractive measures are taken accordingly because the fluctuation is either not detected or neglected by operators.

\subsection{Blast Temperature}

An analysis has been conducted for 10 degrees centigrade of blast temperature. The test results are shown in Fig. 2. In all figures of this paper the dotted lines are for the base case. The results suggest that the thermal level of the furnace is higher due to the increased heat input of the whole furnace.

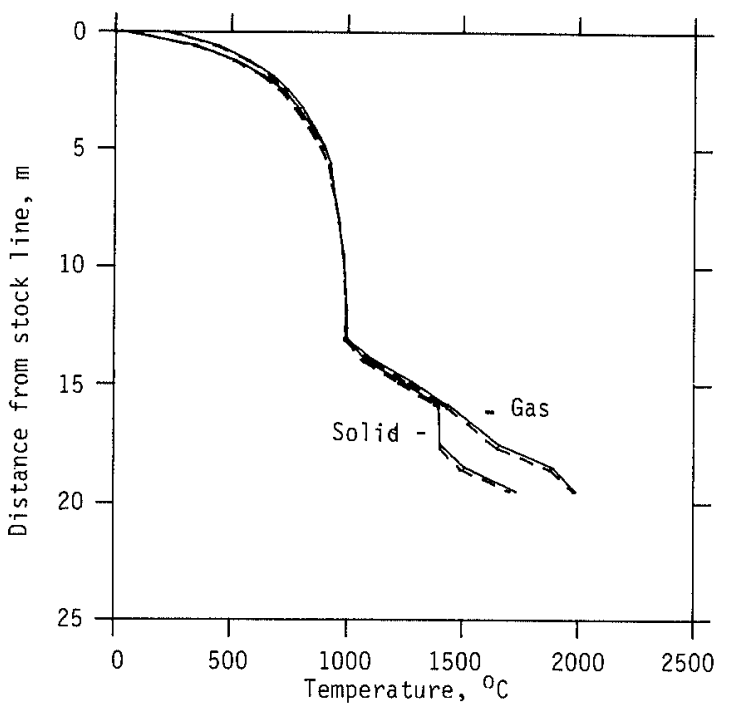

Fig. 2. Change in the thermal condition for $10^{\circ} \mathrm{C}$ increase of blast temperature.

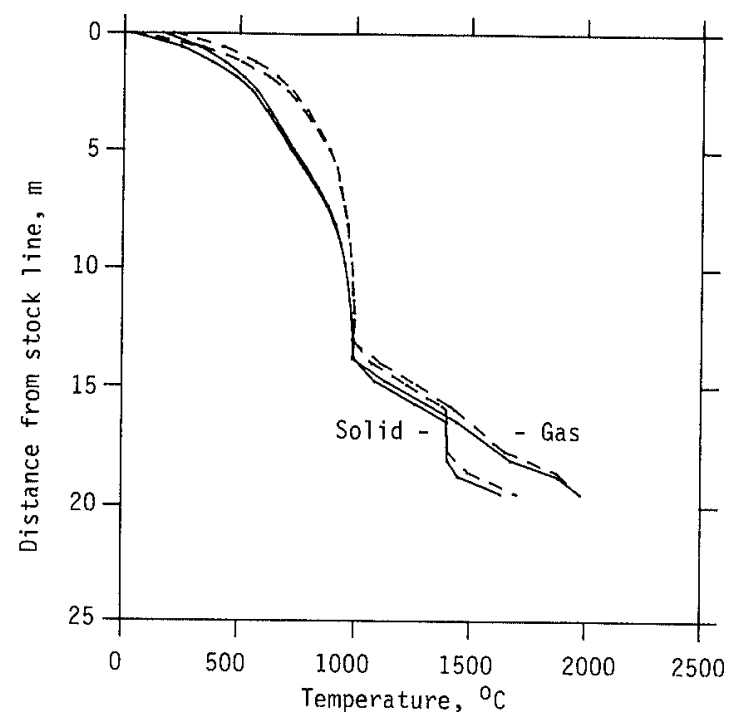

Fig. 3. Change in the thermal condition for $+1 \%$ increase of coke moisture.

\subsection{Coke Moisture}

An analysis has been carried out for $1 \%$ increase of coke moisture, and the results are shown in Fig. 3. It is obvious that the furnace thermal level becomes higher, and that the temperature of the condensed phases at the tuyere level decreases. This is due to decreased input of dry coke, and consequently decreased heat input of the whole furnace.

\subsection{Iron Content in the Ore}

An analysis has also been carried out for $0.5 \%$ increase of iron content in the ore. The test results are shown in Fig. 4. It is clear that the thermal level of the furnace becomes lower, and that the temperature of the condensed phases at the tuyere level decreases. This is due to the decreased coke consumption and heat input of the whole furance.

The analysis above illustrate the importance to reduce fluctuation of the operating parameters, especially coke moisture and $\mathrm{Fe}$ content in the ores, in order to obtain a stable operation.

\section{Prediction of Operating Indices}

It is very interesting to predict the internal state of the furnace and the operating indices before an operating action is to be undertaken. At present, the model has been built up to predict the effect of the following five operating actions:

ACTION 1 -increased blast temperature,

ACTION 2 - oxygen enrichment of blast,

ACTION 3 - coal powder injection,

ACTION 4-combination of coal powder injection and oxygen enrichment, and

ACTION 5 - changed coke quality.

\subsection{Prediction Results}

Predictions have been performed based on the simulation results of $\mathrm{BF}$ A. ${ }^{1)}$

\subsubsection{Increased Blast Temperature}

Three levels were chosen for the prediction test. The

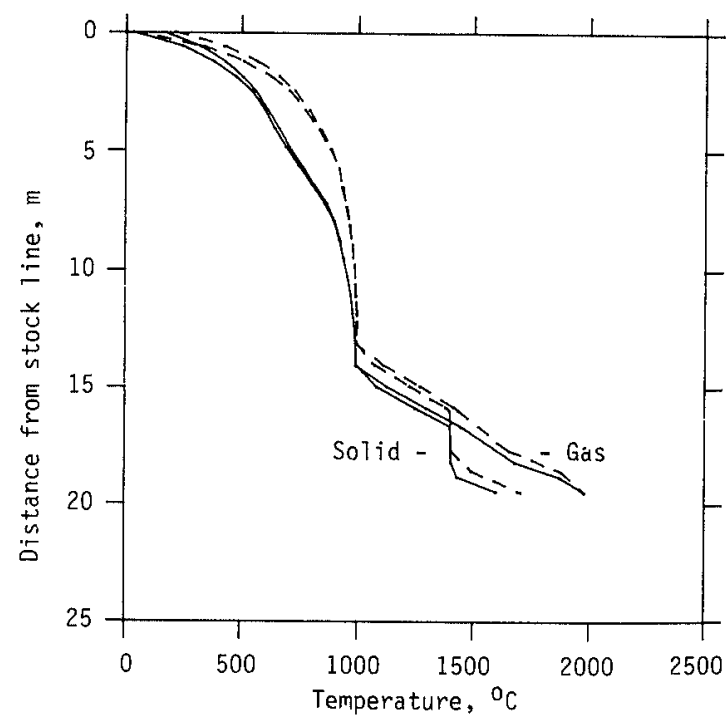

Fig. 4. Change in the thermal condition for $0.5 \%$ increase of $\mathrm{Fe}$ content in the ore. 
Table 1. Prediction results of BF A for increased blast temperature.

\begin{tabular}{|c|c|c|c|c|}
\hline Blast temperature $\left({ }^{\circ} \mathrm{C}\right)$ & 1033 & 1083 & 1133 & 1183 \\
\hline $\mathrm{O} / \mathrm{C}$ ratio & 3.442 & 3.483 & 3.519 & 3.551 \\
\hline $\mathrm{O} / \mathrm{F}$ ratio & 3.426 & 3.467 & 3.504 & 3.535 \\
\hline Total heat input (GJ/THM) & 4.135 & 4.107 & 4.090 & 4.085 \\
\hline Coke consumption (kg/THM) & 460.1 & 454.8 & 450.1 & 446.1 \\
\hline Fuel consumption (kg/THM) & 462.3 & 456.8 & 452.1 & 448.1 \\
\hline Hot metal production ( $\mathrm{t} /$ day) & 2199 & 2262 & 2320 & 2371 \\
\hline$\Delta($ coke $),(\mathrm{kg} / \mathrm{THM})$ & - & -5.3 & -10.0 & -14.0 \\
\hline Variation of coke consumption (\%) & —. & -1.2 & -2.2 & -3.1 \\
\hline$\Delta$ (fuel), (kg/THM) & - & -5.5 & -10.2 & -14.2 \\
\hline Variation of fuel consumption $(\%)$ & - & -1.2 & -2.2 & -3.1 \\
\hline Variation of hot metal production (\%) & - & +2.9 & +5.5 & +7.8 \\
\hline Blast volume $\left(\mathrm{Nm}^{3} / \mathrm{THM}\right)$ & 1109 & 1059 & 1033 & 1029 \\
\hline Gas volume $\left(\mathrm{Nm}^{3} / \mathrm{THM}\right)$ & 1617 & 1583 & 1553 & 1527 \\
\hline $\begin{array}{l}\text { Temperature of top gas at the } \\
\text { stock line }\left({ }^{\circ} \mathrm{C}\right)\end{array}$ & 206 & 182 & 167 & 159 \\
\hline $\begin{array}{l}\text { Position of the ending point of } \\
\text { melting zone }(\mathrm{m})\end{array}$ & 17.86 & 17.32 & 17.24 & 17.1 \\
\hline The volume of the dropping zone $\left(\mathrm{m}^{3}\right)$ & 75.4 & 99.7 & 103.2 & 109.0 \\
\hline
\end{tabular}

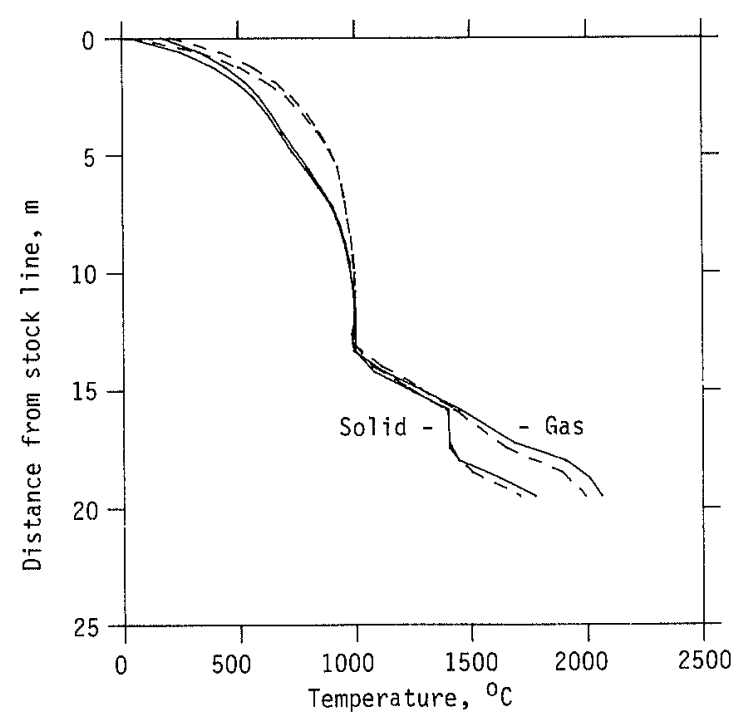

Fig. 5. Predicted temperature distributions for the case of $100^{\circ} \mathrm{C}$ increased blast temperature.

prediction results are given in Table 1. The profile of the gas and condensed phase temperatures is illustrated in Fig. 5, and the profiles in the base case, i.e. the simulation test, are also presented in the figure. The predicted effects of this operating action are shown in Fig. 6.

The most interesting information obtained from the prediction when increasing the blast temperature are:

- Both fuel consumption and coke consumption decreases with increasing blast temperature. This is due to the substitution of higher blast enthalpy for fuel combustion heat and decreased top gas enthalpy.

- Furnace productivity increases as a constant blast volume is used and fuel consumption decreases.

- Direct reduction degree slightly increases due to insufficient heating of iron ores in the lumpy zone.

- Total heat input to the furnace decreases slightly which indicates that the heat carried into the furnace by hot blast may be employed more efficiently than that supplied by the fuel.

Silicon transfer phenomena are not taken into con-

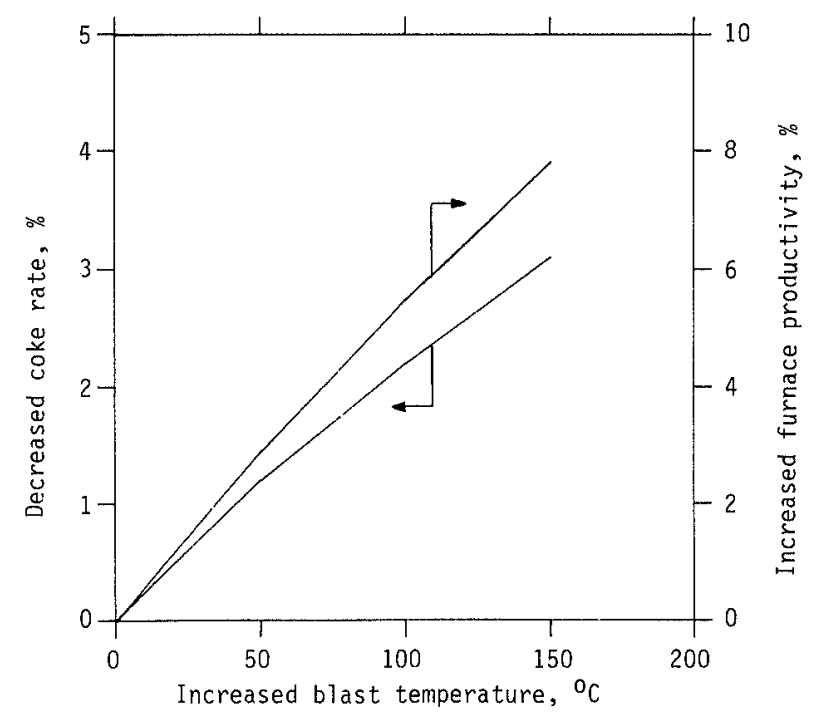

Fig. 6. Predicted effects of increased blast temperature.

sideration in the $\mathrm{KTH}$ model at present, but because the flame temperature and volume of the dropping zone increase it is suggested that $[\% \mathrm{Si}]$ in the hot metal may increase.

The decrease in coke consumption predicted by the $\mathrm{KTH}$ model is $2.2 \% / 100^{\circ} \mathrm{C}$ when the blast temperature is increased from 1033 to $1133^{\circ} \mathrm{C}$. This result was compared to data reported in the literature. According to Schumacher ${ }^{3)}$ a coke saving of about $4 \% / 100^{\circ} \mathrm{C}$ at $900^{\circ} \mathrm{C}, 3 \% / 100^{\circ} \mathrm{C}$ at $1000^{\circ} \mathrm{C}$ and $2 \% / 100^{\circ} \mathrm{C}$ at $1100^{\circ} \mathrm{C}$ can be obtained for a furnace of high coke ratio operation $\left(635 \mathrm{~kg} / \mathrm{THM}\right.$, at a blast temperature of $\left.850^{\circ} \mathrm{C}\right)$. According to $\mathrm{Wegman}^{4)}$ a coke saving of $2.3 \% / 100^{\circ} \mathrm{C}$ from 1000 to $1100^{\circ} \mathrm{C}$ can be achieved for a modern blast furnace. As to furnace productivity, an increase of $5.5 \% / 100^{\circ} \mathrm{C}$ from 1033 to $1133^{\circ} \mathrm{C}$ was predicted by the model. This figure was also compared to operational data. According to Schumacher ${ }^{3)}$ an increase of about $27 \%$ by increasing the blast temperature from 850 to $1250^{\circ} \mathrm{C}$, i.e. $6.8 \% / 100^{\circ} \mathrm{C}$, can be obtained. It is interesting to see that the results predicted by the KTH model agree reasonably well with these oper- 
Table 2. Prediction results of BF A for oxygen enrichment of blast.

\begin{tabular}{|c|c|c|c|c|}
\hline Oxygen enrichment $(\%)$ & 0.00 & 0.50 & 1.00 & 1.50 \\
\hline $\mathrm{O} / \mathrm{C}$ ratio & 3.442 & 3.435 & 3.425 & 3.415 \\
\hline $\mathrm{O} / \mathrm{F}$ ratio & 3.426 & 3.420 & 3.410 & 3.400 \\
\hline Total heat input (GJ/THM) & 4.135 & 4.115 & 4.102 & 4.091 \\
\hline Coke consumption (kg/THM) & 460.1 & 461.0 & 462.4 & 463.8 \\
\hline Fuel consumption (kg/THM) & 462.3 & 463.1 & 464.5 & 465.8 \\
\hline Hot metal production ( $\mathrm{t} /$ day) & 2199 & 2241 & 2279 & 2316 \\
\hline$\Delta($ coke $),(\mathrm{kg} / \mathrm{THM})$ & - & +0.9 & +2.3 & +3.7 \\
\hline Variation of coke consumption (\%) & - & +0.19 & +0.49 & +0.80 \\
\hline$\Delta($ fuel $),(\mathrm{kg} / \mathrm{THM})$ & - & +0.8 & +2.2 & +3.5 \\
\hline Variation of fuel consumption $(\%)$ & - & +0.18 & +0.48 & +0.77 \\
\hline Variation of hot metal production $(\%)$ & - & +1.9 & +3.6 & +5.3 \\
\hline Blast volume $\left(\mathrm{Nm}^{3} / \mathrm{THM}\right)$ & 1109 & 1088 & 1070 & 1053 \\
\hline Gas volume $\left(\mathrm{Nm}^{3} / \mathrm{THM}\right)$ & 1617 & 1597 & 1579 & 1562 \\
\hline $\begin{array}{l}\text { Temperature of top gas at the } \\
\text { stock line }\left({ }^{\circ} \mathrm{C}\right)\end{array}$ & 206 & 200 & 197 & 195 \\
\hline $\begin{array}{l}\text { Position of the ending point of } \\
\text { melting zone }(\mathrm{m})\end{array}$ & 17.86 & 17.75 & 17.76 & 17.77 \\
\hline The volume of the dropping zone $\left(\mathrm{m}^{3}\right)$ & 75.4 & 80.2 & 79.9 & 79.2 \\
\hline
\end{tabular}

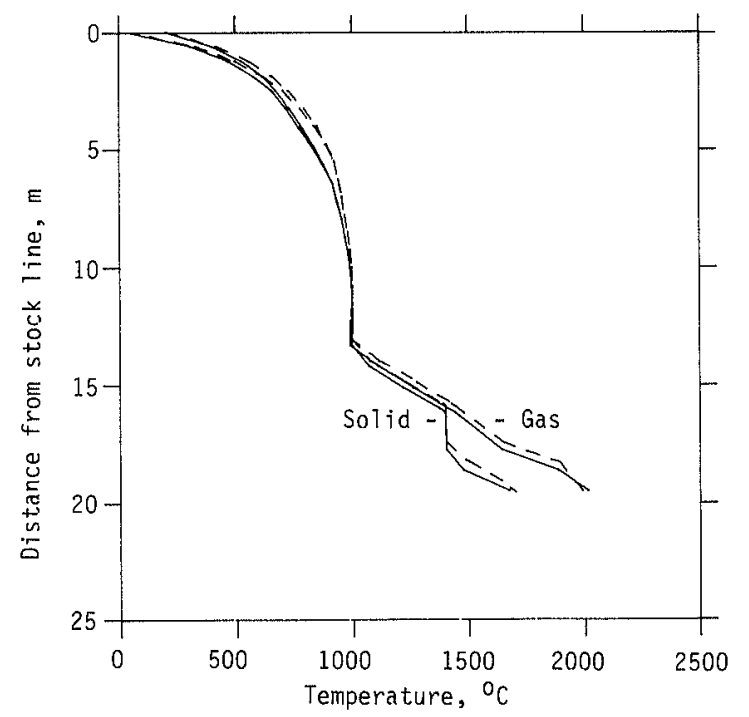

Fig. 7. Predicted temperature distributions for the case of $1 \%$ oxygen enrichment of the blast.

ational data.

\subsubsection{Oxygen Enrichment of the Blast}

Three levels of oxygen enrichment of the blast were chosen for prediction by the KTH-model. The results are given in Fig. 7, Table 2 and Fig. 8.

The following information obtained from the predictions is interesting:

- Both fuel consumption and coke consumption increase slightly. This is caused by the decreased CO utilization, $\eta_{\mathrm{co}}$.

- Furnace productivity increases due to the increased mass flowrate of oxygen.

- The flame temperature and dropping zone volume increase compared to the base case.

It is found that the volume of the dropping zone decreases with increasing of oxygen enrichment. The action of oxygen enrichment has two effects, i.e. increasing the flame temperature and furnace productivity. The former effect will lead to increased dropping zone volume, which is shown by the results of the computer tests of analysing the thermal condition for the

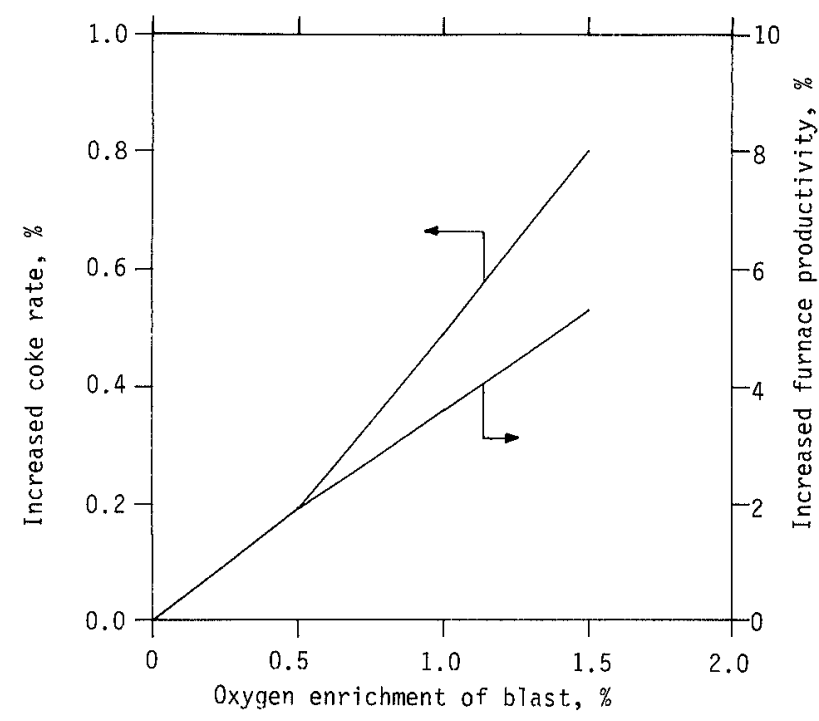

Fig. 8. Predicted effects of oxygen enrichment of the blast.

case of blast temperature fluctuation. According to a computer analysis by the model of the thermal condition in the case of an increased furnace productivity with the blast volume being increased and the heat input being constant, the latter effect will lead to a decreases in the volume of the dropping zone. It could be considered that the latter effect becomes stronger when the blast is more oxygen enriched. As a result, the volume of the dropping zone decreases when the amount of oxygen enrichment is higher.

It should be pointed out that the increased fuel consumption, which is predicted in this study, is only valid for the case when the raceway gas volume is kept constant with increasing oxygen content in the blast. The reason is that the furnace productivity will increase, and, consequently, that the $\mathrm{CO}$ utilization will decrease in this case. If the furnace productivity is kept constant when the blast is oxygen-enriched the fuel consumption will decrease due to increased $\mathrm{CO}$ utilization.

\subsubsection{Coal Powder Injection}

Several levels of coal powder injection were chosen for 
Table 3. Prediction results of $\mathrm{BF} A$ for coal powder injection.

\begin{tabular}{|c|c|c|c|c|}
\hline Mass flowrate of coal powder $(\mathrm{kg} / \mathrm{hr})$ & 0.00 & 4000 & 8000 & 12000 \\
\hline $\mathrm{O} / \mathrm{C}$ ratio & 3.442 & 3.784 & 4.201 & 4.732 \\
\hline $\mathrm{O} / \mathrm{F}$ ratio & 3.426 & 3.410 & 3.390 & 3.370 \\
\hline Total heat input (GJ/THM) & 4.135 & 4.123 & 4.127 & 4.130 \\
\hline Coke consumption ( $\mathrm{kg} / \mathrm{THM})$ & 460.1 & 418.6 & 377.0 & 334.8 \\
\hline Coal consumption (kg/THM) & 0.0 & 43.8 & 88.2 & 133.1 \\
\hline Fuel consumption (kg/THM) & 462.3 & 464.5 & 467.3 & 470.1 \\
\hline Hot metal production ( $t /$ day) & 2199 & 2193 & 2178 & 2163 \\
\hline$\Delta($ coke $),(\mathrm{kg} / \mathrm{THM})$ & - & -41.5 & -83.1 & -125.3 \\
\hline Variation of coke consumption (\%) & - & -9.03 & -18.07 & -27.24 \\
\hline$\Delta($ fuel $),(\mathrm{kg} / \mathrm{THM})$ & - & +2.2 & +5.0 & +7.8 \\
\hline Variation of fuel consumption (\%) & - & +0.5 & +1.1 & +1.7 \\
\hline Replacement ratio of coal to coke & - & 0.949 & 0.943 & 0.941 \\
\hline Variation of hot metal production (\%) & - & -0.3 & -1.0 & -1.7 \\
\hline Blast volume $\left(\mathrm{Nm}^{3} / \mathrm{THM}\right)$ & 1109 & 1112 & 1120 & 1128 \\
\hline Gas volume $\left(\mathrm{Nm}^{3} / \mathrm{THM}\right)$ & 1617 & 1643 & 1674 & 1705 \\
\hline $\begin{array}{l}\text { Temperature of top gas at the } \\
\text { stock line }\left({ }^{\circ} \mathrm{C}\right)\end{array}$ & 206 & 226 & 253 & 280 \\
\hline $\begin{array}{l}\text { Position of the ending point of } \\
\text { melting zone }(\mathrm{m})\end{array}$ & 17.86 & 17.89 & 18.14 & 18.15 \\
\hline The volume of the dropping zone $\left(\mathrm{m}^{3}\right)$ & 75.4 & 67.9 & 62.6 & 58.8 \\
\hline
\end{tabular}

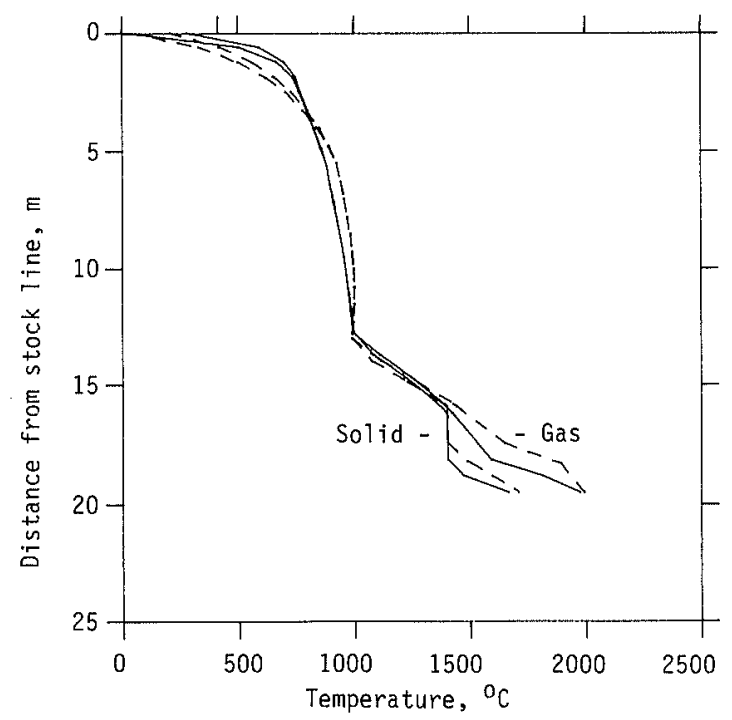

Fig. 9. Predicted temperature distributions for the case of $133.1 \mathrm{~kg} /$ THM coal powder injection.

prediction. The volatile matter content in the coal is $26 \%$. The prediction results are given in Fig. 9 and Table 3.

The following information obtained from the prediction is valuable:

- Coke consumption decreases.

- Fuel consumption slightly increases because $\eta_{\mathrm{co}}$ decreases and top gas enthalpy increases. The replacement ratio of coal, i.e. $\mathrm{kg}$ (coke) $/ \mathrm{kg}$ (coal), in this example is between 0.9 and 1.0 .

- $[\% \mathrm{Si}]$ in the hot metal may drop because both the flame temperature and dropping zone volume decreases.

Practical operation results of coal injection depend not only on the coal properties but also on the efficiency of furnace operation. This fact should be kept in mind when any comparison between model prediction results and empirical results is made. Trials of coal injection were conducted on BF 4 of Hamborn, Thyssen Co.,

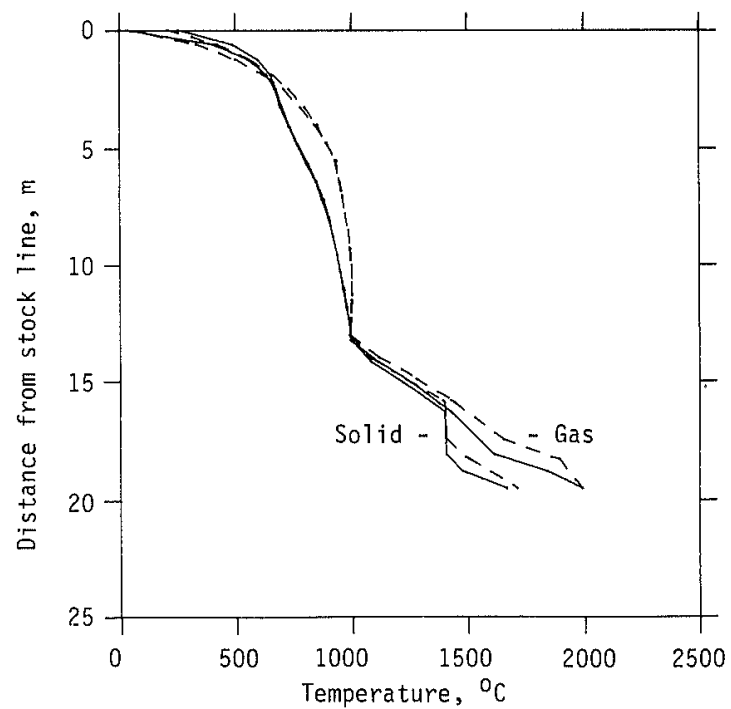

Fig. 10. Predicted temperature distributions for the case of $107.8 \mathrm{~kg} / \mathrm{THM}$ coal powder injection and oxygen enrichment to keep constant flame temperature.

West Germany 1986.5) The coke ash content, natural air blast and proportion of sinter and pellets in the burden in the trials are similar to the conditions for the prediction in this study. When $136 \mathrm{~kg}$ coal powder per ton of hot metal was injected a coke consumption of $338 \mathrm{~kg} / \mathrm{THM}$ was achieved in the trials. According to model test by the $\mathrm{KTH}$ model, coke saving is influenced by the replacement ratio of coal to coke. The higher the ratio, the bigger the coke saving. The replacement ratio in the prediction is 0.94 compared to 0.84 in the trials. This could be the reason why the coke consumption in the prediction is roughly the same as the empirical one although $100^{\circ} \mathrm{C}$ lower blast temperature was used for the prediction.

\subsubsection{Coal Injection Combined with Oxygen Enrich- ment}

Predictions for three levels of coal injection rates 54.1, 
Table 4. Prediction results of BF A for coal powder injection and oxygen enrichment.

\begin{tabular}{|c|c|c|c|c|}
\hline Mass flowrate of coal powder $(\mathrm{kg} / \mathrm{hr})$ & 0.00 & 5000 & 12000 & 20000 \\
\hline Oxygen enrichment (\%) & 0.000 & 0.250 & 0.563 & 1.463 \\
\hline $\mathrm{O} / \mathrm{C}$ ratio & 3.442 & 3.877 & 4.407 & 6.245 \\
\hline $\mathrm{O} / \mathrm{F}$ ratio & 3.426 & 3.408 & 3.375 & 3.395 \\
\hline Total heat input (GJ/THM) & 4.135 & 4.100 & 4.090 & 3.998 \\
\hline Coke consumption (kg/THM) & 460.1 & 408.6 & 359.5 & 253.7 \\
\hline Coal consumption $(\mathrm{kg} / \mathrm{THM})$ & 0.0 & 54.1 & 107.8 & 211.0 \\
\hline Fuel consumption (kg/THM) & 462.3 & 464.8 & 469.4 & 466.7 \\
\hline Hot metal production ( $\mathrm{t} / \mathrm{day}$ ) & 2199 & 2218 & 2225 & 2275 \\
\hline$\Delta($ coke $),(\mathrm{kg} / \mathrm{THM})$ & - & $-5 I .5$ & -100.6 & -206.4 \\
\hline Variation of coke consumption $(\%)$ & - & -11.3 & -21.9 & -44.9 \\
\hline$\Delta$ (fuel), (kg/THM) & - & +2.5 & +7.1 & +4.4 \\
\hline Variation of fuel consumption $(\%)$ & - & +0.5 & +1.5 & +0.95 \\
\hline Replacement ratio of coal to coke & - & 0.958 & 0.934 & 0.978 \\
\hline Variation of hot metal production (\%) & - & +0.8 & +1.2 & +3.5 \\
\hline Blast volume $\left(\mathrm{Nm}^{3} / \mathrm{THM}\right)$ & 1109 & 1100 & 1096 & 1072 \\
\hline Gas volume $\left(\mathrm{Nm}^{3} / \mathrm{THM}\right)$ & 1617 & 1635 & 1661 & 1677 \\
\hline $\begin{array}{l}\text { Temperature of top gas at the } \\
\text { stock line }\left({ }^{\circ} \mathrm{C}\right)\end{array}$ & 206 & 224 & 250 & 303 \\
\hline $\begin{array}{l}\text { Position of the ending point of } \\
\text { melting zone }(\mathrm{m})\end{array}$ & 17.86 & 17.94 & 18.09 & 18.76 \\
\hline The volume of the dropping zone $\left(\mathrm{m}^{3}\right)$ & 75.4 & 71.9 & 64.9 & 32.2 \\
\hline
\end{tabular}

Table 5. Prediction results of $\mathrm{BF} A$ for changed coke quality.

\begin{tabular}{|c|c|c|c|}
\hline $\begin{array}{l}\text { Starting temperature of } \\
\text { solution loss }\left({ }^{\circ} \mathrm{C}\right)\end{array}$ & 933.9 & 1000 & 1066.1 \\
\hline $\mathrm{O} / \mathrm{C}$ ratio & 3.431 & 3.442 & 3.454 \\
\hline $\mathrm{O} / \mathrm{F}$ ratio & 3.415 & 3.426 & 3.438 \\
\hline Total heat input (GJ/THM) & 4.136 & 4.135 & 4.132 \\
\hline Coke consumption (kg/THM) & 461.7 & 460.1 & 458.6 \\
\hline Fuel consumption ( $\mathrm{kg} / \mathrm{THM})$ & 463.8 & 462.3 & 460.7 \\
\hline Hot metal production ( $\mathrm{t} /$ day) & 2199.0 & 2199.4 & 2201.2 \\
\hline$\Delta$ (coke),$(\mathrm{kg} / \mathrm{THM})$ & +1.6 & - & -1.5 \\
\hline $\begin{array}{l}\text { Variation of coke } \\
\text { consumption }(\%)\end{array}$ & +0.3 & - & -0.3 \\
\hline$\Delta($ fuel $),(\mathrm{kg} / \mathrm{THM})$ & +1.5 & - & -1.6 \\
\hline $\begin{array}{l}\text { Variation of fuel } \\
\text { consumption }(\%)\end{array}$ & +0.3 & - & +0.3 \\
\hline CO utilization $(-)$ & 0.4854 & 0.4908 & 0.4960 \\
\hline Blast volume $\left(\mathrm{Nm}^{3} / \mathrm{THM}\right)$ & 1109.08 & I 108.86 & 1107.94 \\
\hline Gas volume $\left(\mathrm{Nm}^{3} / \mathrm{THM}\right)$ & 1619.80 & I 617.0 & 1613.51 \\
\hline $\begin{array}{l}\text { Temperature of top gas at } \\
\text { the stock line }\left({ }^{\circ} \mathrm{C}\right)\end{array}$ & 200.1 & 206.0 & 211.0 \\
\hline Thickness of lumpy zone (m) & 12.93 & 13.05 & 13.93 \\
\hline $\begin{array}{l}\text { Thickness of softening } \\
\text { zone }(\mathrm{m})\end{array}$ & 3.02 & 2.83 & 2.32 \\
\hline Thickness of melting zone (m) & 1.60 & 1.59 & 1.30 \\
\hline $\begin{array}{l}\text { Position of the ending point } \\
\text { of melting zone (m) }\end{array}$ & 17.55 & 17.48 & 17.55 \\
\hline $\begin{array}{l}\text { The volume of the dropping } \\
\text { zone }\left(\mathrm{m}^{3}\right)\end{array}$ & 72.4 & 75.4 & 72.5 \\
\hline
\end{tabular}

107.8 and $211 \mathrm{~kg} / \mathrm{THM}$, which are correspond to 5000 , 12000 and $20000 \mathrm{~kg} / \mathrm{hr}$ respectively, with appropriate oxygen contents to keep the flame temperatures constant were conducted. The results are given in Table 4 and Fig. 10. The following information obtained from the predictions is notable.

- Coke consumption decreases.

- Fuel consumption increases slightly.

- Furnace productivity increases slightly.

- The raceway gas volume increases.

The extent of all the changes for this combined action case is less than that for pure coal powder injection.

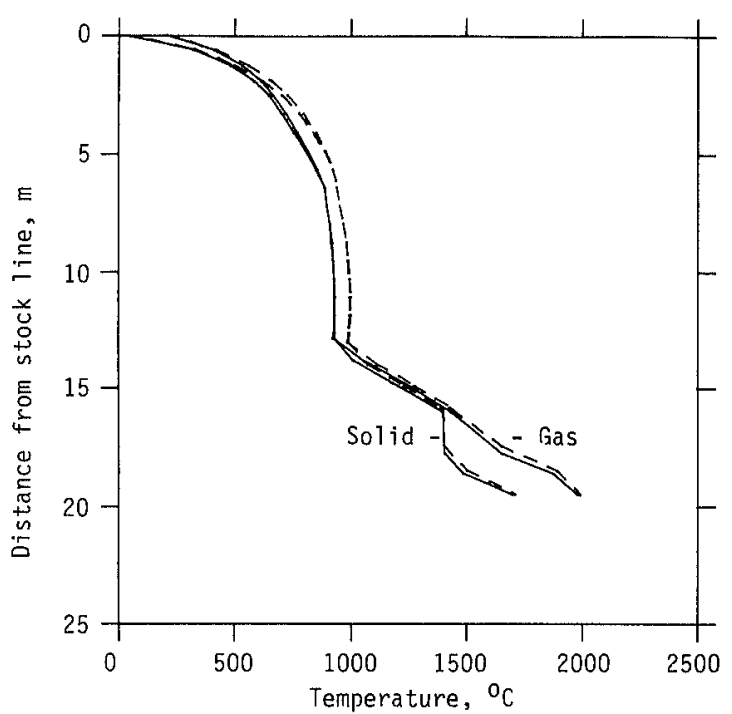

Fig. 11. Predicted temperature distributions for the case of increased coke reactivity $\left(66.1^{\circ} \mathrm{C}\right.$ decreased starting temperature of the solution loss reaction)

\subsubsection{Changed Coke Quality}

The starting temperature of the solution loss reaction in the blast furnace is influenced by the coke quality. Hatano et al. ${ }^{6)}$ presented an expression that links the starting temperature, the coke quality and the accumulated alkalis in the furnace. The starting temperature increases with increasing coke size and decreasing coke reactivity and alkali amount in the furnace. Two levels of changed starting temperature, i.e. +66.1 and $-66.1^{\circ} \mathrm{C}$ which are comparable to $-10 \%$ and $+10 \%$ coke reactivity according to Hatano's expression by neglecting the influence of coke size and accumulated alkali, were selected for prediction. The test results are shown in Table 5, Figs. 11 and 12.

The following information obtained from the prediction for higher coke quality is valuable:

- Both coke consumption and fuel consumption decreases slightly due to an increased $\mathrm{CO}$ utilization. 


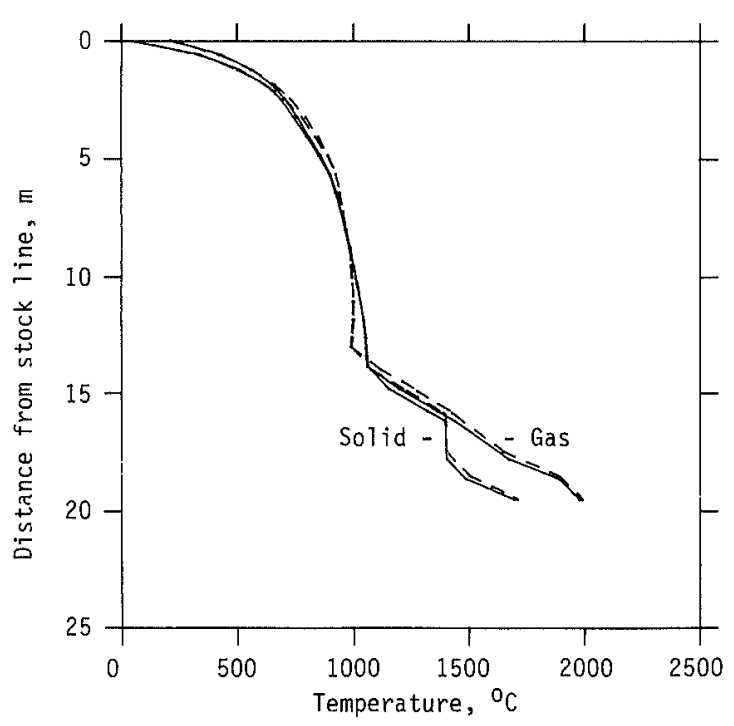

Fig. 12. Predicted temperature distributions for the case of decreased coke reactivity $\left(66.1^{\circ} \mathrm{C}\right.$ increased starting temperature of the solution loss reaction).

- Furnace productivity increases slightly.

It is noticed that the volume of the dropping zone decreases when coke quality changes. This observation may be explained as follows. When coke quality is high the volume of the lumpy zone becomes bigger which results in decreased dropping zone volume, in spite of smaller volume of the softening and melting zones (see Table 5). In contrast, if coke quality is low, the volume of the softening and melting zones become bigger, which leads to decreased dropping zone volume, although the volume of the lumpy zone is smaller.

\section{Concluding Remarks}

A one-dimensional static model for simulation and prediction of the blast furnace process has been developed at the Department of Process Metallurgy, The Royal Institute of Technology (KTH), Sweden. The validity of the KTH model is supported by the comparison of the predicted resultes for some operational actions with industrial test data. This model can be used for:

- obtaining a deeper understanding of the metallurgical aspects of the blast furnace process (research and personnel training), and

- prediction of the internal state in the blast furnace, fuel consumption and furnace productivity when blast parameters and injection rates are changed (operation policy, management and production planning). It is possible to develop the model further so that prediction can be made for the change in other operating parameters.

These two functions are important for a successful control of the blast furnace process.

\section{Acknowledgements}

This work is sponsored by the Swedish Ironmasters' Association (Jernkontoret). Thanks are sent to Professor Sven Eketorp for his critical remarks during the manuscript preparation. Techn Lic. Tor Borinder and
Mr. Rutger Gyllenram are gratefully acknowledged for their help and fruitful discussions throughout the work. Thanks are also due to Mr. Anwar Jamil for his assistance with some programming work, and to $\mathrm{Mr}$. Carl-Lennart Axelsson for valuable discussions on programming.

\section{Nomenclature}

$\mathrm{CO}_{g}^{0}$ : $\mathrm{CO}$ content of top gas (volume fraction)

$\mathrm{CO}_{2, g}^{0}: \mathrm{CO}_{2}$ content of top gas (volume fraction)

$\mathrm{CO}_{2, g}^{1}$ : calculated $\mathrm{CO}_{2}$ content of gas as the temperature of the solids is equal to the starting temperature of the solution loss reaction (volume fraction)

$f_{s}^{0}:$ degree of iron ore reduction at the stock line $(-)$

$h_{p}$ : coefficient for heat transfer between the gas and condensed phases $\left(\mathrm{kJ} / \mathrm{m}^{2} \cdot \mathrm{h} \cdot{ }^{\circ} \mathrm{C}\right)$

$h_{w}$ : coefficient for heat losses through the furnace wall $\left(\mathrm{kJ} / \mathrm{m}^{2} \cdot \mathrm{h} \cdot{ }^{\circ} \mathrm{C}\right)$

$H_{2, g}^{0}: \quad \mathrm{H}_{2}$ content of top gas (volume fraction)

$R_{1}^{*}$ : overall reaction rate of ore reduction by $\mathrm{CO}$ $\left(\mathrm{kmol}(\mathrm{CO}) / \mathrm{m}^{3}\right.$ (bed) $\left.\cdot \mathrm{h}\right)$

$T_{g}^{0}$ : gas temperature at the stock line $(\mathrm{K})$

$T_{g}^{1}$ : lower boundary condition at the tuyere level of gas temperature, i.e. the flame temperature (K)

$T_{g, 4}$ : calculated gas temperature at the tuyere level (K)

$T_{s}^{1}$ : lower boundary condition of the condensed phase temperature at the tuyere level $(\mathrm{K})$

$T_{s, 4}$ : calculated temperature of condensed phases at the tuyere level $(\mathrm{K})$

$\eta_{\mathrm{co}}:$ CO utilization of gas (-)

$\eta_{\mathrm{H}_{2}}: \mathrm{H}_{2}$ utilization of gas (-)

$\gamma_{\mathrm{co}}$ : degree of $\mathrm{FeO}$ reduction by $\mathrm{CO}(-)$

$\gamma_{d}$ : direct reduction degree of $\mathrm{FeO}$ by carbon (-)

$\gamma_{\mathrm{H}_{2}}$ : degree of FeO reduction by $\mathrm{H}_{2}(-)$

$\psi_{1 i}$ : correction factor for $h_{w}(-), i=1,2,3$ is for the lumpy zone, the softening/melting zone and the dropping zone, respectively.

$\psi_{2 i}$ : correction factor for $R_{1}^{*}(-), i=1,2,3$ is for the lumpy zone, the softening/melting zone and the dropping zone, respectively.

$\psi_{3 i}$ : correction factor for $h_{p}(-), i=1,2,3$ is for the lumpy zone, the softening/melting zone and the dropping zone, respectively.

$\rho_{s}^{0}$ : density of the condensed phases at the stock line $\left(\mathrm{kg} / \mathrm{m}^{3}\right)$

\section{REFERENCES}

1) X. Bi, K. Torssell and O. Wijk: ISIJ Int., 32 (1992), 470.

2) R. D. Pehlke: Unit Processes of Extractive Metallurgy, Second Printing, Elsevier Publishing Co., Inc., New York, (1975), 314.

3) H. Schumacher: Stahl Eisen, 86 (1966), 313.

4) Eu. F. Wegmann: A Reference Book for Blast Furnace Operators, Trans. from Russian into English by V. Afanasyev, Mir Publishers, Moscow, (1984), 202.

5) M. Giuli, G. Hanniker, J. Koster, K. Kreibich, J. M. van Langen, Y. de Lassat de Pressigny and A. Pcos: Proc. European Iron-making Cong. 1986 in Aachen, West Germany, IV/2, 17.

6) M. Hatano, T. Miyazaki and Y. Iwanaga: Sumitomo Search, (1980), No. 23, 1 . 